Presentations were made by Professor Jenny FirthCozens on occupational stress in health professionals, and on 'burn-out', and by Dr Matt Muijen on the pressures on in-patient beds.

A paper entitled An Analysis of the Concerns of Consultant General Psychiatrists About their Jobs, and of the Changing Practices that may Point Towards Solutions by Dr Peter Kennedy and Dr Hugh Griffiths (2000) of the Northern Centre for Mental Health was circulated to the group.

\section{References}

DEPARTMENT OF HEALTH (2000) An Organisation With a Memory. London: Department of Health.

KENNEDY, P. \& GRIFFITHS, H. (2000) An Analysis of the Concerns of
Consultant General Psychiatrists about theirJobs, and of the Changing Practices that may Point Towards Solutions. Durham

City: Northern Centre for Mental Health.

Psychiatric Bulletin (2001), 25, 444-446

ARTHUR CRISP

\title{
Changing Minds: Every Family in the Land
}

\section{A campaign update}

Our 5-year long campaign to reduce the stigmatisations of and discriminations against people with mental illnesses, launched as an outline endeavour in October 1998 , is now in its third year. This update is intended to reveal that since 1998 we have been constructively busy and are poised to 'go public' in major ways. We are now therefore appealing to the membership at large to join in the tasks. To this end we have been busy generating a tool kit that you may wish to draw upon and a series of proposed projects, some of which are already underway and some of which you may be able to pick up on or adapt for local purposes, in addition to any of your own initiatives.

\section{Tool kit}

The management committee hopes that this is now sufficiently developed to provide a useful resource of instruments to advance the campaign. We shall continue to add to this kit.

The central campaign website is part of the College website and can be accessed directly (http:// www. changingminds. co.uk/campaigns/cminds/index. $\mathrm{htm}$ ). It is now being robustly developed and is intended as an engine continuing to promote the objectives after the campaign itself has come to an end in 2003. Its current contents include the controversial and much sought after 2-minute '1 in 4' film (which has been adopted by the World Health Organization (WHO) for its own mental illness anti-stigma purposes). The campaign website provides links to other recommended relevant websites. The other campaign-related website (http:// www.stigma.org/everyfamily/) holds a 200000 -word, 400-page electronic book addressing stigmatisations of people with any of the six mental disorders being addressed by the campaign. These are examined from a variety of perspectives - historical; contemporary (e.g. experiences of users and of those working within health care systems); legislative; the nature of basic mechanisms within the stigmatising and discriminatory processes; relationships to creativity, spirituality and to personality disorders; and types of interventions. The 80 contributors include Anthony Clare, David Goldberg, Kay Redfield Jamieson, Roy Porter, Lewis Wolpert and many other well-known and respected experts. A CD-ROM version is available and it is also hoped a conventionally printed and bound text will be produced.

Printed materials within the tool kit include periodic campaign updates and posters. We hope that members will use the campaign posters, which are A3 size. They include the campaign logo and outline message and have plenty of blank space that can be used to advertise local meetings and to elaborate on the campaign's goals.

Finally, the kit includes a listing of videotapes, in particular the campaign video (available respectively at a cost of $f 5$ and $f 10$ from the campaign administrator, Liz Cowan, Royal College of Psychiatrists, 17 Belgrave Square, London SW1X 8PG), a video of the ' 1 in 4 ' film and, as well as a listing of other recommended videotapes and information about how to obtain them.

\section{Projects}

Working parties have so far generated proposals for 17 potential projects targeting four main areas - the general public, children and young adults, employers and doctors and other healthcare workers. Their universal implementation is dependent upon funding. There has been one fundraising event sponsored by Saatchi and Saatchi and another is planned for Autumn 2001. So far, nearly $\mathrm{f} 150000$ has been raised in addition to the invaluable core financial support that comes from the College and the substantial donation of resources and expertise by WCRS, a major advertising company, necessary for the making of the 2-minute cinema film. 
Box 1 Categories of the main recommendations of the report - Mental Illness: Stigmatisation and Discrimination within the Medical Profession (CR91) (Royal College of Psychiatrists et al, 2001)

Government, NHS trusts, the General Medical Council (GMC), Royal Colleges, the British Medical Association and other health care organisations should:

(a) make clear statements about the unacceptability of stigmatisation

(b) promote campaigns to raise awareness and to combat stigmatisation of people with mental illnesses by doctors

(c) adopt procedures to ensure that discrimination, when discovered, is challenged and acted upon.

Medical schools, the GMC, Royal Colleges and postgraduate deaneries should ensure that:

(a) existing guidance about the training of doctors in relation to attitudes towards and assessment of people with mental illnesses, including competence in examining the mental state, is implemented for all medical students and doctors

(b) related diagnostic labelling is not at the expense of recognition of and respect for the uniqueness of the individual

(c) specific guidance is developed to ensure that the selection of medical students and doctors is not subject to discrimination on grounds of mental health problems. As with physical illnesses and disabilities, selection should be based on a realistic assessment of the applicant's health and of any likely effect on his or her patients.

Mental health of medical students and doctors

(a) Systems should continue to be developed for identifying and dealing sensitively with medical students and doctors with mental health problems.

(b) An occupational health service for all doctors is essential.

To further promote the above recommendations there would be advantage in:

(a) mounting a national conference on stigmatisation of people with mental illnesses by doctors and liaise with the media, including professional journals, to encourage relevant coverage

(b) using the anticipated input from other campaign working parties, e.g. those currently considering schizophrenia, drug and alcohol addiction and origins of stigmatisation

(c) using the variety of campaign tools

(d) conducting further research into doctors' attitudes.

\section{The general public}

Proposed projects include a television and poster-based communication campaign, hugely ambitious but with Saatchi and Saatchi willing to provide freely the creative input if we can find a sponsor. A high quality photographic exhibition addressing stigmatisation of people with eating disorders is a probable starter, as must be the fourth project in this area - the proposed repeat survey in 2004 of public opinions concerning people with the mental illnesses that the campaign has been addressing.

\section{Children and young people}

Six projects are under consideration and some of them are underway. For instance, a set of four comic books for 4- to 7-year olds, conveying how it feels to be 'different', were launched in July and are being marketed to schools and the general public as well as the membership (Comic Company, 2001). A series of cartoon booklets Coping with Hurting (currently awaiting production) aims to enable teenagers to react with understanding and care to people close to them with mental illnesses. A third project seeks simply to produce many thousand more copies of Headstuff, the highly successful pamphlet that was made available in Warner Brothers cinema foyers at the time that the 2 -minute film '1 in 4' was being shown up and down the country. Another project in this area aims to produce a debriefing resource pack to accompany this film when it is used in the future as an instrument aiming to change attitudes and increase knowledge among young people.

\section{Employers}

There are four projects now ready to start. At the time of writing they all await proper funding. One aims to promote the establishment of optimal drug and alcohol policies and guidelines for accessing effective treatment in all companies. Another offers a training programme for human resources officers and managers. Another proposes extensive local educational programmes.

\section{Health care professionals}

There are three projects in this area. One involves an extensive educational programme at 70 centres the length and breadth of the country over the course of 
2 weeks during December 2001 in the first instance, aimed at engaging general practitioners. We especially need your help with this and please contact the

special articles campaign administrator, Liz Cowan, if you would like to know more about it.

Finally, one major project has been developed to tackle the stigmatisation of people with mental illnesses by doctors. This project has been developed by a working party involving collaboration between our College, the Royal College of Physicians and the British Medical Association. The Royal College of General Practitioners has also been involved, as has the Department of Health and user representatives. The Royal College of Nursing has had an observer present. This report was formally published in July 2001 as College Council Report, CR91 (Royal College of Psychiatrists et al, 2001). Against a background of acknowledging that such stigmatisation and discrimination exists, the report makes a series of recommendations (Box 1) and many of these are now being implemented. It is clear to the management committee that doctors in all specialities, including psychiatry, can be at fault and we are delighted that so many other postgraduate professional bodies within medicine have seen fit to join us enthusiastically in this task. Clearly, this is an area where involvement of the membership over the next few years can make a great difference.

In conclusion, I want to reiterate yet again that the management committee believes our campaign will now benefit greatly from energetic and professional input from the College's faculties, sections, special interest groups and divisions, and from the membership at large. Instruments and projects are now in place to facilitate this. The campaign needs to be owned and promoted by us all. Please contact the campaign office (tel: 02072352351 ext 122; fax: 0207235 1935; e-mail: Icowan@rcpsych.ac.uk) for more details and any guidance that you would welcome.

\section{References}

COMIC COMPANY (2001) Reading Lights. London: Comic Company \& Royal College of Psychiatrists.

ROYAL COLLEGE OF PSYCHIATRISTS, ROYAL COLLEGE OF PHYSICIANS OF LONDON \& BRITISH MEDICAL

ASSOCIATION (2001) Mental Illness: Stigmatisation and Discrimination Within the Medical Profession. Council Report CR91. London: Royal College of Psychiatrists, Royal College of Physicians of London \& British Medical Association.

Professor Arthur Crisp Chairman, Campaign Management Committee

Psychiatric Bulletin (2001), 25, 446-448

\section{BOB GROVE}

\section{Making work schemes work}

The past 5 years have seen dramatically increased interest among users, professionals and the Government in enabling people with mental health problems to gain employment. Many new projects have been started, with a range of different approaches including supported employment, training and placement, transitional employment, social firms and cooperatives. There are a number of reasons for this increased interest.

First, users themselves want to work, as is confirmed in a whole range of quality of life and user surveys (Pozner et al, 1996a,b; Rinaldi \& Hill, 2000). This aspiration is not confined to those who have recently lost their job but extends, according to one survey, to around half of those who have lost touch with the labour market over an extended period (Bates, 1996).

Second, employment improves the quality of people's lives - in more ways than relieving their poverty. Many studies have demonstrated that meaningful occupation is a critical factor in clinical improvement, improved social functioning and reduction of symptoms (Schneider, 1998). A study of Irish social firms showed how work can be a significant factor in people staying out of a hospital and reducing their use of medication and day treatment centres (McKeown et al, 1992). Studies also show that there are strong links between unemployment and mental ill health (Warr, 1987) and a prob- able link with increased risk of suicide (Platt \& Kreitman, 1984; Mueser et al, 1987).

Third, there is increasing political support for the view that high levels of unemployment among people with disabilities, including those with mental health problems, is unnecessarily wasteful of lives and a denial of civil rights. A special report for the Labour Force Survey of 2000 suggests that there is an unemployment rate of $82 \%$ for people with a psychiatric disability (Labour Source Survey Autumn 2000; http://www. drc-gb.org/drc/InformationAndLegislation/Page354.asp). This compares with studies in the UK, US and Germany that suggest that, given appropriate support, $30 \%$ or more of people with a diagnosis of severe mental disorder are capable of holding down a job (Ekdawi \& Conning, 1994; Drake et al, 1996; Seyfried, 1995).

There are, however, serious barriers to employment that mental health service users have to overcome some of them within mental health services themselves. Clinical and social care services often compound the very real problems of stigma and discrimination from employers and the general public by having as their basis the implicit assumption that they are there to support people out of work rather than in work. Many services are also poor value for money. Studies of the comparative costs of keeping people in hospitals and day centres as against supporting them in employment show that the 